\title{
IMPROVED AUTOMATIC APPARATUS FOR PHARMACOLOGICAL ASSAYS ON ISOLATED PREPARATIONS
}

\author{
BY \\ A. BOURA, J. L. MONGAR, AND H. O. SCHILD \\ From the Department of Pharmacology, University College, London
}

(RECEIVED JULY 25, 1953)

Every pharmacological assay on isolated plain muscle involves certain routine procedures such as emptying and refilling the isolated organ bath, adding one or more drugs to the bath, recording the contraction on a moving drum and allowing an interval for recovery of the tissue. Automatic apparatus for performing these various repetitive manipulations has been described before and has been in use in this and other laboratories for some time (Schild, 1946, 1947; Bülbring, 1949; Gaddum and Lembeck, 1949; Godfrey, Mogey, and Taylor, 1950; Bovet and Virno, 1952). We have found apparatus of this kind especially useful in assays involving the repetitive administration of a limited number of doses (three- and four-point assays) and in experiments in which the activities of antagonistic and potentiating drugs are measured; these drugs often produce irreversible effects and it is important that their actions be assessed against the background of a steady preparation.

In the apparatus previously described (Schild, $1946,1947)$ the filling and emptying of the isolated organ bath was automatically controlled; but the drug had to be injected by hand, and the relative duration of the various stages of the assay cycle was fixed. We now describe a more adaptable, fully automatic apparatus, which can be used for most types of assay work on isolated preparations. The duration of each stage of the cycle is independently variable and can be adjusted to the response of the tissue; the assay solutions are added automatically in a predetermined but adjustable order; and an antagonistic or potentiating drug may be introduced at some stage in the cycle. The principle of controlling the flow of liquid by compressing rubber tubing with modified telephone relays, previously described, is retained in the present apparatus; but control is now on the air flow into the vessels containing the drug and washing solutions, so that the solutions do not come in contact with rubber tubing. They are rapidly brought from room temperature to the temperature of the bath as they flow through a thin-walled, jacketed warming tube. A jacketed isolated organ bath, which can be as small as $1 \mathrm{ml}$., and which is completely emptied before adding the drug solution, is used. In this way small quantities of dilute solutions may be assayed.*

\section{Principle of Operation}

The schematic diagram of Fig. 1 shows the manner in which solutions are stored and warmed and the method of emptying and filling the isolated organ bath. A and E represent electromagnetic valves which compress rubber tubing. When $\mathrm{A}$ is opened, air enters the reservoir $\mathrm{B}$ and Ringer or drug solution flows out through the jacketed warming tube $C$ into the isolated organ bath $D$. When valve $E$ is opened the solution flows out of the bath. Six reservoirs are provided, four containing active drug and two Ringer solution or an antagonistic or potentiating drug. These solutions are not diluted further before reaching the tissue and the reservoirs must therefore contain the drugs in their final dilutions.

The valves are operated at predetermined but easily adjustable intervals in such a way that the drug is brought in contact with the tissue for the required time and then removed by repeated emptying and refilling of the bath with Ringer solution. The timing of the operations is controlled by a switching unit. Impulses sent out by an electronic timer energize the driving magnets of a uniselector causing the wipers to move on to the next contact. At certain contacts of the uniselector new values of variable condensers and resistances in the timing circuit are switched in, thus altering the length of time that elapses before the next impulse is sent out. The contacts on the uniselector are wired to the valves in such a way that a complete assay cycle is carried out for each half revolution of the uniselector. Two sets of controls are provided, one to determine the duration and sequence of various steps in the assay cycle and the other to determine the sequence in which drugs are introduced

\footnotetext{
* This apparatus is now made by Casella (Electronics) Ltd.
} 
into the bath (dose cycle). The dose cycle is controlled by a second uniselector.

Assay Cycle.-The assay cycle is divided into seven stages:

1. Emptying of isolated organ bath.

2. Refilling of bath with Ringer solution.

3. First resting period.

4. Second resting period.

5. Emptying of isolated organ bath.

6. Refilling of bath with drug solution.

7. Drug contact period.

The duration of each stage can be independently varied, that of stage $1,2,5$ and 6 between $\frac{1}{2}$ and $500 \mathrm{sec}$. and that of stage 3,4 and 7 between $2 \frac{1}{2}$ and 2,500 sec.

This basic cycle can be modified in various ways. The main modifications are:

1. The washing of the tissue with Ringer solution (stage 1 and 2) can be repeated several times.

2 . An antagonistic or potentiating drug can be introduced after stage 3 and left in contact with the tissue during stage 4 .

3. Drugs can be administered by hand. A concentrated drug solution is introduced with a syringe, after adjustment of the bath level by an automatic overflow (stages 5 and 6 omitted); or a diluted drug solution is added by pipette through the warming tube (stage 6 omitted).

The rotation of the kymograph is automatically controlled. It can be switched on for a variable part of the cycle.

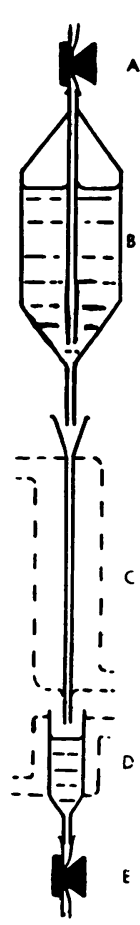

Dose Sequence.-A sequence of 24 doses of 4 different drug solutions can be automatically administered in any desired order depending on the position of 24 wander plugs on the control panel. The dose-order circuit has been primarily designed for four-point assays, employing randomized sequences of four drug solutions, but a completely random sequence of 24 doses, or a systematic sequence, may be adopted. It is also possible to exclude one, two or three drug reservoirs and limit the sequence to the remainder: thus a single drug may be administered indefinitely. The present circuit could be readily modified to control 6 or more drug solutions.

Control Panel.-Table I describes in detail the various modifications of the cycle which can be achieved according to the setting of the switches on the control panel.

FIG. 1.-Diagram illustrating the manner in which drug and Ringer solutions are stored, and warmed whilst flowing into the isolated organ bath. $A$ and $E$, electromagnetic valves. $B$, reservoir for Ringer or drug solution. C, jacketed warming tube. D, jacketed organ bath. For further explanation, see text.
TABLE I

SETTING OF SWITCHES ON CONTROL PANEL TO MODIFY ASSAY CYCLE

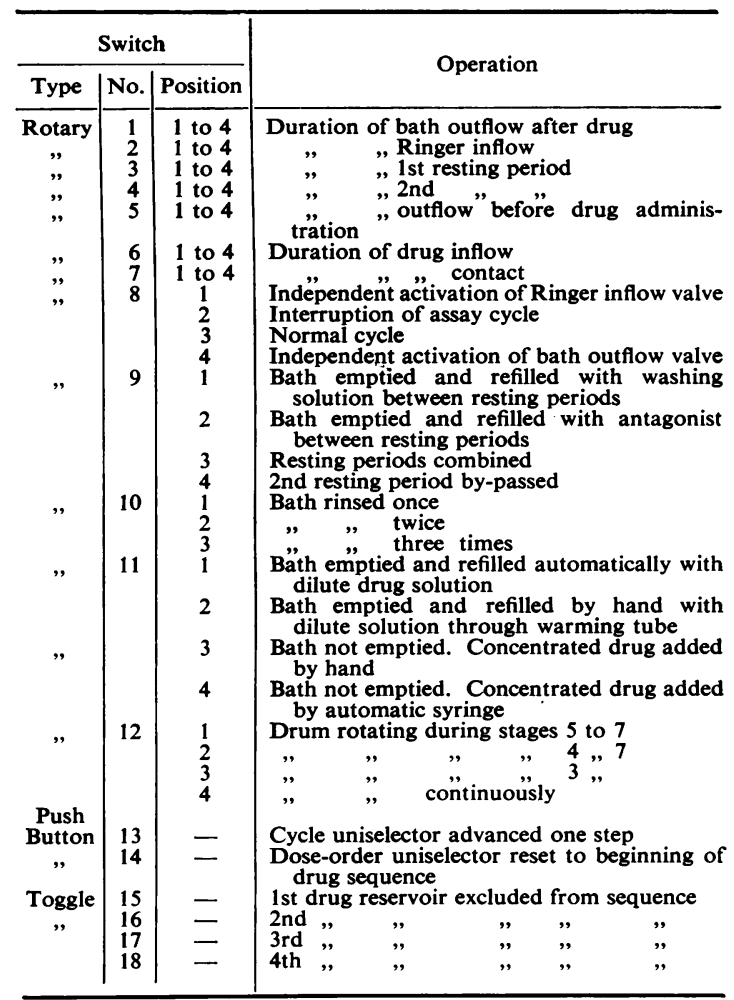

In addition to the switches listed in the table the control panel contains :

(a) seven linear potentiometers to provide fine adjustment for switches 1 to 7 .

(b) A switch board containing 24 wander plugs to determine the drug sequence. Four sets of 6 plugs, each corresponding with the four drug solutions, can be plugged into sockets to produce any desired order of doses.

\section{Construction of Apparatus}

Isolated Organ Apparatus.-The isolated-organ bath, warming tube and solution reservoirs are shown in detail in Fig. 2. The particular arrangement illustrated has been designed for the repeated addition of four different drug solutions. It is important that these solutions be added at a uniform rate and that they should reach the bath by a final common path so that systematic errors are avoided.

The drug solutions are stored in vessels fitted with ground glass stoppers which carry air-inlet tubes. When the valve compressing the rubber tubing attached to the air-inlet tube is energized, air enters the reservoir and the solution flows out through a capillary tubing. Care has been taken to keep the hydrostatic pressure and the resistance of the outflow tube constant. The air-inlet tube extends nearly to the bottom of the vessel, producing a hydrostatic pressure independent of the liquid level in 
the reservoir. The dimensions of the air inlet and capillary outlet tubes of each of the drug reservoirs are similar. The ends of the delivery tubes have a ground glass surface making contact with the inside of the funnel at the top of the warming tube; surface tension effects are thereby minimized and the solutions flow into the warming tube at similar rates. The ground glass tips are bevelled in such a way that the flow is not impeded (inset of Fig. 2).

The vertical warming tube consists of a thin-walled glass tube about $3 \mathrm{~mm}$. in diameter surrounded by a jacket through which warm water circulates. If the tube is quite clean the solutions flow down the walls in a thin film and rapid heating is obtained. A tube $20 \mathrm{~cm}$. long with a jacket temperature of $38^{\circ} \mathrm{C}$. can warm a flow of $10 \mathrm{ml} . / \mathrm{min}$. from $20^{\circ}$ to $36^{\circ} \mathrm{C}$. The warming system has a negligible hold-up so that there is no mixing of one solution with another.

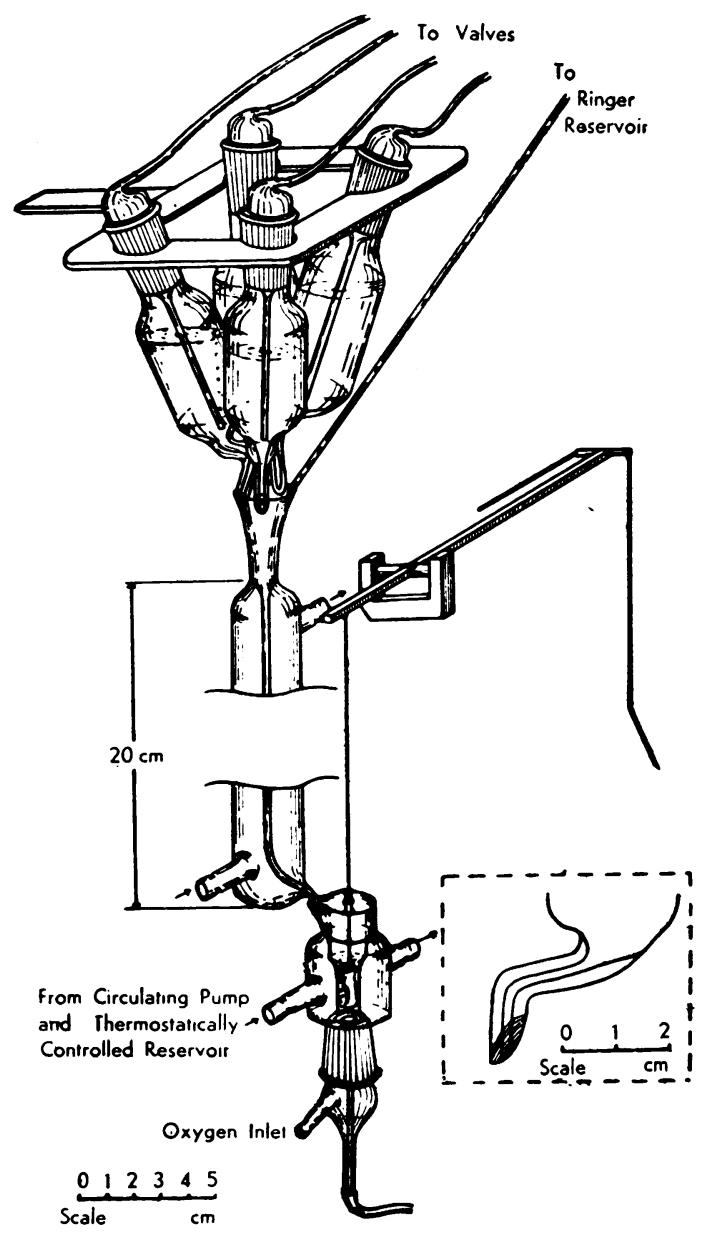

Fig. 2.-Drug reservoirs, warming tube and isolated-organ bath. Inset illustrates the bevelled end of the drug delivery tube. For explanation, see text.

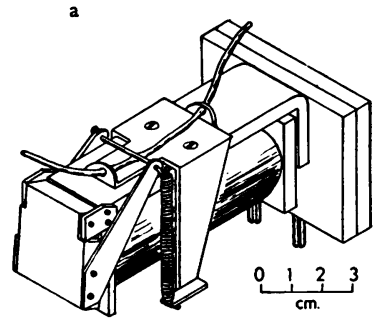

Fig. 3.-Modified telephone relays used to compress rubber tubing. Valve (a) is used on the air-inlet tube. Valve (b) has a small hold-up and is used for the bath outlet. Resistance of coils $=$ 300 ohms. When the coils are energized the valves open.
The isolated organ bath itself is in the form of a jacketed tube about $7 \mathrm{~mm}$. in diameter and $20 \mathrm{~mm}$. long. This is suitable for small preparations such as the guinea-pig ileum. A bath $12 \mathrm{~mm}$. in diameter and $50 \mathrm{~mm}$. long has been used for bulkier preparations. The top is enlarged slightly and has an indentation to receive the end of the heating tubs. The bottom is closed by a ground glass joint which carries the liquid outlet, oxygen inlet and a bridge-piece to which the lower end of the tissue is attached.

Valves.-These operate on the principle of compressing rubber tubing by means of modified telephone relays. This simple method of controlling flow has been found to be entirely satisfactory it thin-walled surgical quality tubing of 1 to $2 \mathrm{~mm}$. bore is used. The valves are easily made; the type illustrated in Fig. 3a is used for controlling the air inlet of the solution reservoirs; the type in Fig. $3 b$ is used on the liquid outlet of the bath.

Control Circuits.-The electrical part of the apparatus can be divided into three circuits-the electronic timer the cycle uniselector circuit controlling the various operations of the assay cycle, and the dose-order circuit.

The circuits are described in detail in Figs. 4 and 5 and the accompanying legends. The timer circuit is shown in the upper part of Fig. 4. It utilizes the first two banks of the cycle uniselector. The circuit was designed by Mr. V. Attree. The cycle circuit utilizes the third, fourth and fifth banks of the uniselector as shown in the lower part of Fig. 4. The third bank of contacts is wired to indicator lights, one for each stage of the assay cycle. The fourth bank controls eight electromagnetic valves regulating flow-namely, bath outlet; 


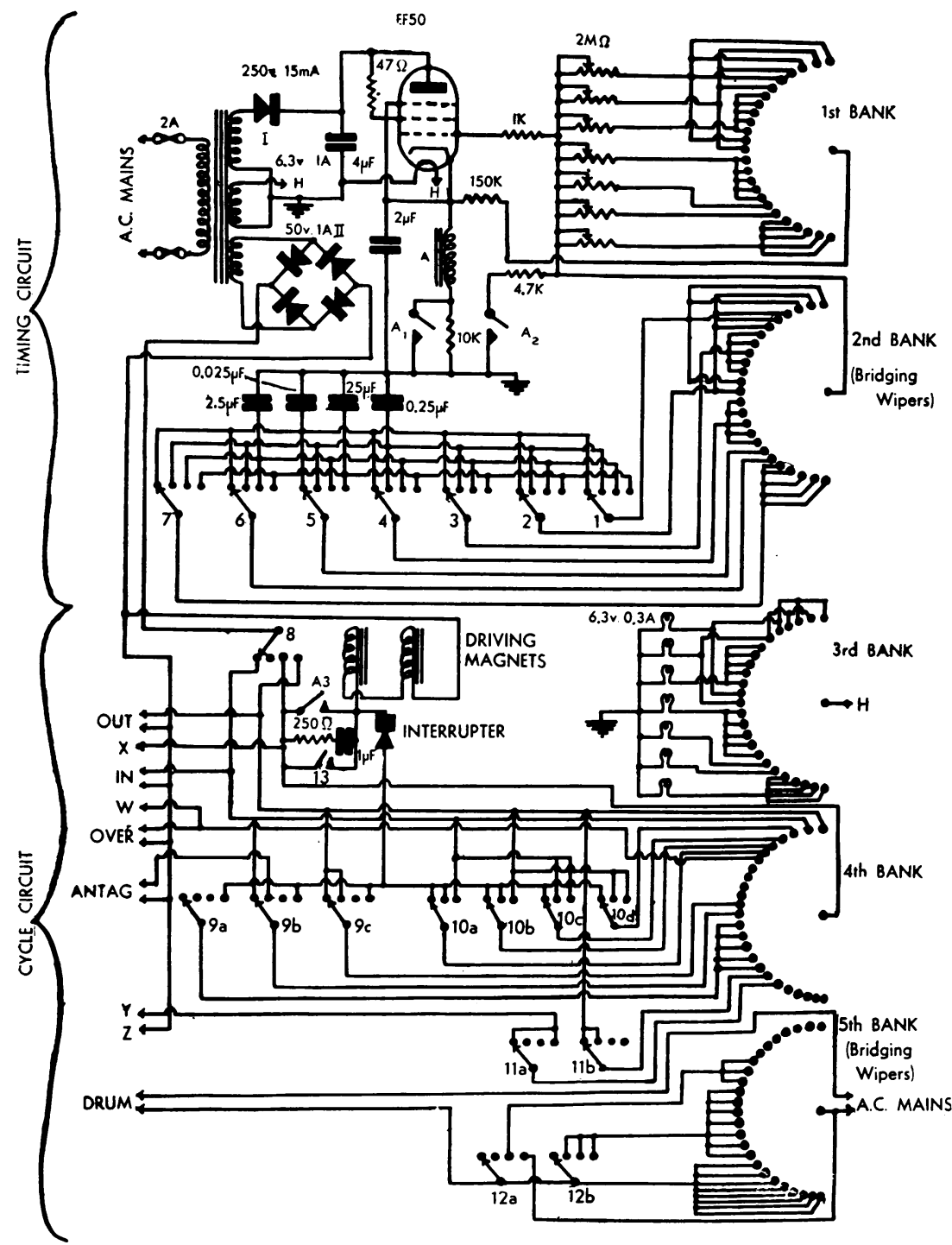

FIG. 4.-Timing and assay cycle circuit. The timing circuit occupies the first two banks of the uniselector and the assay circuit the last three banks. A standard Post Office uniselector (type 89A fitted with bank contacts, type 80) with two driving magnets each of 37.5 ohms resistance, is used. Relay A (P.O. type 3,000, coil resistance 20,000 ohms) should be so adjusted that $\mathbf{A}_{1}$ closes before $\mathbf{A}_{2}$ and $\mathbf{A}_{3}$; by shorting the $10 \mathrm{~K}$ resistance, contacts $A_{1}$ cause the relay to snap over rapidly, thus reducing sparking on $A_{3}$. Rectifiers I and II are Standard Telephones and Cables type S.B.3 and B.45-4-1FW, respecon $\mathrm{A}_{3}$. Rectifiers $\mathrm{I}_{\text {and }}$ an are $\mathrm{Standard}_{\text {tively. }}$ All resistances are rated at 1 watt. All condensers are $350 \mathrm{~V}$. W. low loss paper condensers tively. All resistances are rated at $\frac{1}{2}$ watt. All condensers are 350 . W. low loss paper condensers
except the smoothing condenser $(4 \mu \mathrm{F})$ which may be of the electrolytic type. OUT-Connexion to outflow valve of isolated organ bath. IN-Connexion to inflow valve of Ringer solution. OVER -Connexion to overfiow valve controlling constant volume of bath. ANTAG.-Connexion to antagonist or potentiator inflow valve. DRUM-Connexion to kymograph. W, X, Y and $\mathrm{Z}$ connect to corresponding points in the drug selector circuit. Numbers correspond to switches in Table I.

washing solution inlet; bath overflow; to adjust the bath level; antagonist or potentiating solution inflow; and inflows for four drug solutions. The valves are activated in the sequence shown in Table II. It will be seen that the 25 steps of the cycle uniselector are subdivided into 3 long periods of 5 steps each, comprising the drug contact and the two resting periods and 10 short periods of 1 step. The fifth bank of contacts is used to switch on the drum at a suitable point in the assay cycle and to switch it off when the bath is emptied of drug solution. The 
TABLE II

SEQUENCE OF OPERATIONS IN THE ASSAY CYCLE

\begin{tabular}{|c|c|c|c|c|c|c|c|c|c|c|c|c|c|c|c|c|c|c|c|c|c|c|c|c|c|}
\hline \multirow{2}{*}{$\begin{array}{l}\text { Period: } \\
\begin{array}{l}\text { Stage No: } \\
\text { Selector } \\
\text { contact : }\end{array}\end{array}$} & \multicolumn{6}{|c|}{ 1st, 2nd \& 3rd washing } & \multicolumn{5}{|c|}{ 1st resting period } & \multicolumn{2}{|c|}{$\begin{array}{l}\text { Addi- } \\
\text { tional } \\
\text { washing }\end{array}$} & \multicolumn{5}{|c|}{ 2nd resting period } & \multicolumn{2}{|c|}{$\begin{array}{c}\text { Drug } \\
\text { added }\end{array}$} & \multicolumn{5}{|c|}{$\begin{array}{l}\text { Drug in contact } \\
\text { with tissue }\end{array}$} \\
\hline & $\begin{array}{l}1 \\
1\end{array}$ & $\begin{array}{l}2 \\
2\end{array}$ & $\begin{array}{l}1 \\
3\end{array}$ & $\begin{array}{l}2 \\
4\end{array}$ & $\begin{array}{l}1 \\
5\end{array}$ & $\begin{array}{l}2 \\
6\end{array}$ & $\begin{array}{l}3 \\
7\end{array}$ & $\begin{array}{l}3 \\
8\end{array}$ & 3 & $\begin{array}{c}3 \\
10\end{array}$ & $\begin{array}{c}3 \\
11\end{array}$ & $\begin{array}{c}1 \\
12\end{array}$ & $\begin{array}{c}2 \\
13\end{array}$ & $\begin{array}{l}4 \\
14\end{array}$ & $\begin{array}{c}4 \\
15\end{array}$ & \begin{tabular}{c|}
4 \\
16
\end{tabular} & $\begin{array}{c}4 \\
17\end{array}$ & $\begin{array}{c}4 \\
18\end{array}$ & $\begin{array}{c}5 \\
19\end{array}$ & $\begin{array}{c}6 \\
20\end{array}$ & $\begin{array}{c}7 \\
21\end{array}$ & $\begin{array}{c}7 \\
22\end{array}$ & $\begin{array}{c}7 \\
23\end{array}$ & $\begin{array}{c}7 \\
24\end{array}$ & $\begin{array}{c}7 \\
25\end{array}$ \\
\hline $\begin{array}{l}\text { Operation } \\
\text { performed: }\end{array}$ & 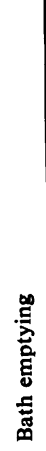 & 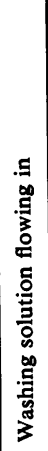 & 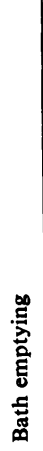 & 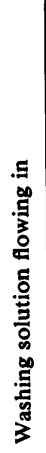 & 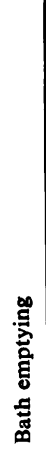 & 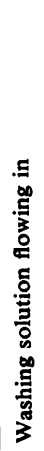 & 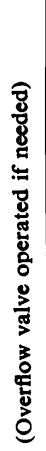 & & & & & 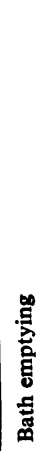 & 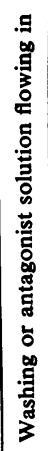 & & & & & & 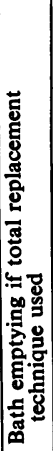 & 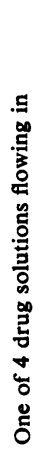 & & & & & \\
\hline
\end{tabular}

dose-order circuit is shown in Fig. 5. It employs a second uniselector which normally advances one step for each assay cycle. When certain drugs are switched out of the

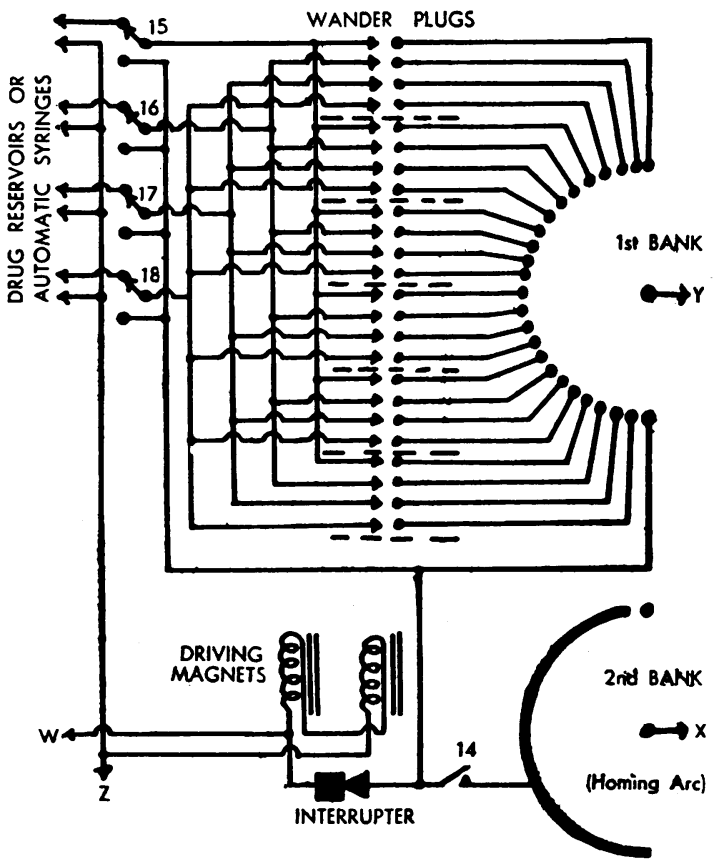

FIG. 5.-Dose-order circuit. One bank of the uniselector (P.O. type 42A fitted with bank contacts No. 42, each coil of 37.5 ohms) 42A fitted with bank contacts No. 42, each coil of 37 , or to automatic injection syringes. The second bank is a homing arc automatic injection syringes. The second bank is a homing arc
which returns the uniselector to the first contact. Numbers correspond to switches in Table I. circuit the corresponding contacts are jumped by using the interrupter on the uniselector.

\section{USE OF APPARATUS}

As an example of the use of the apparatus, its application to the assay of dilute solutions of histamine on the guinea-pig ileum will be described. The control panel of the switching unit is set up as follows :
Stage 1. Emptying and draining of bath
2-3 sec.
2. Refilling with Ringer solution
$5-6 \mathrm{sec}$.
3. First resting period .. ..
15-30 sec.
4. Second resting period .. by-passed
5. Emptying of bath before addi- tion of drug $\quad$.. $\quad$. $\quad 1$ sec.
6. Refilling with drug solution. . 4-5 sec.
7. Drug contact period. . .. $15 \mathrm{sec}$.

If the interval between operations 5 and 6 is kept as short as possible, spontaneous contractions during the change-over are usually negligible and do not interfere with the assay. The contraction after the drug has been introduced takes $12 \mathrm{sec}$. to reach a maximum; a drug contact period of $15 \mathrm{sec}$. is therefore sufficient. Switch 10 is set for two successive washings. The whole cycle thus takes about one min. The kymograph is started 5 sec. before stage 5 and stopped at the end of stage 7 (S 12-1).

Having set the assay cycle the apparatus is left running, using solutions of $2 \frac{1}{2}, 5,10$, and $20 \times 10^{-\theta}$ histamine. After 30 to $60 \mathrm{~min}$. the responses have become regular, sensitivity is at a maximum and 
the preparation is ready for use. The approximate concentrations of the test solutions, diluted if necessary to lie within the range of sensitivity of the preparation, are determined by adding with a pipette through the warming tube $1 \mathrm{ml}$. of each solution in place of a standard histamine solution (S 11-2). If the response lies within the range covered by the standard solutions the concentration can be estimated by interpolation.

TABLE III

SUMMARY OF HISTAMINE ASSAY RESULTS

(a) Activity of test solutions unknown

(b) Ac, "̈ known

(c) Solütions used repeatedly

\begin{tabular}{|c|c|c|c|c|c|c|}
\hline $\mathbf{N}$ & $\begin{array}{c}\text { Dose } \\
\text { Interval } \\
\text { (secs.) }\end{array}$ & $\left(\frac{U}{S}\right)$ Assay & $\left(\frac{U}{S}\right)$ Theory & $\begin{array}{l}\text { Actual } \\
\text { Error }\end{array}$ & $\begin{array}{c}\text { Limits } \\
\text { of Error } \\
(\mathrm{P}=0.05)\end{array}$ & $\frac{s}{b}$ \\
\hline
\end{tabular}

(a)

\begin{tabular}{|c|c|c|c|c|c|}
\hline $\begin{array}{l}5 \\
3 \\
3 \\
3 \\
3 \\
5 \\
5 \\
5 \\
5 \\
5 \\
5 \\
3 \\
3 \\
3 \\
3 \\
3 \\
3 \\
3 \\
3 \\
5 \\
5\end{array}$ & $\begin{array}{l}38 \\
38 \\
38 \\
38 \\
38 \\
37 \\
36 \\
37 \\
37 \\
37 \\
37 \\
39 \\
39 \\
39 \\
39 \\
39 \\
40 \\
45 \\
45 \\
47 \\
52\end{array}$ & $\begin{array}{l}1.066 \\
1.316 \\
1.257 \\
1.300 \\
1.279 \\
1.055 \\
1.075 \\
1.055 \\
1.081 \\
1.090 \\
1.027 \\
1.167 \\
1.085 \\
1.216 \\
1.088 \\
1.109 \\
1.028 \\
1.253 \\
1.089 \\
1.161 \\
1.194\end{array}$ & $\begin{array}{l}= \\
= \\
= \\
= \\
= \\
= \\
= \\
= \\
= \\
= \\
= \\
=\end{array}$ & $\begin{array}{r}6 \cdot 2 \% \\
4 \cdot 7 \% \\
7 \cdot 0 \% \\
8 \cdot 7 \% \\
4 \cdot 1 \% \\
3.4 \% \\
2 \cdot 3 \% \\
3.4 \% \\
2 \cdot 8 \% \\
3.4 \% \\
4 \cdot 5 \% \\
10 \cdot 0 \% \\
3.7 \% \\
9 \cdot 4 \% \\
5 \cdot 5 \% \\
3.9 \% \\
5 \cdot 9 \% \\
12 \cdot 8 \% \\
5 \cdot 9 \% \\
5 \cdot 5 \% \\
4 \cdot 1 \%\end{array}$ & $\begin{array}{l}.027 \\
.031 \\
.045 \\
.056 \\
.027 \\
.015 \\
.010 \\
.014 \\
.012 \\
.016 \\
.019 \\
.063 \\
.025 \\
.060 \\
.036 \\
.026 \\
.038 \\
.071 \\
.038 \\
.024 \\
.018\end{array}$ \\
\hline
\end{tabular}

\begin{tabular}{|c|c|c|c|c|c|c|}
\hline $\begin{array}{l}5 \\
5 \\
5 \\
5 \\
5 \\
5 \\
5 \\
5 \\
5 \\
5 \\
5 \\
5 \\
5 \\
5 \\
5 \\
5 \\
5 \\
5 \\
5 \\
5 \\
5 \\
5 \\
5 \\
5\end{array}$ & $\begin{array}{l}39 \\
39 \\
39 \\
39 \\
39 \\
38 \\
38 \\
40 \\
58 \\
55 \\
45 \\
45 \\
45 \\
45 \\
45 \\
38 \\
38 \\
45 \\
38 \\
38 \\
40 \\
40 \\
41 \\
42\end{array}$ & $\begin{array}{l}1.257 \\
1.267 \\
1.318 \\
1.226 \\
1.232 \\
1.286 \\
1.294 \\
1.253 \\
1.213 \\
1.268 \\
1.257 \\
1.254 \\
1.257 \\
1.222 \\
1.228 \\
1.297 \\
1.233 \\
1.280 \\
1.234 \\
1.246 \\
1.243 \\
1.047 \\
1.400 \\
1.247\end{array}$ & $\begin{array}{l}1.250 \\
1.250 \\
1.250 \\
1.250 \\
1.250 \\
1.250 \\
1.250 \\
1.250 \\
1.250 \\
1.250 \\
1.250 \\
1.250 \\
1.250 \\
1.250 \\
1.250 \\
1.250 \\
1.250 \\
1.250 \\
1.250 \\
1.250 \\
1.250 \\
1.053 \\
1.250 \\
1.250\end{array}$ & $\begin{array}{l}+0.6 \% \\
+1.4 \% \\
+5.4 \% \\
+1.9 \% \\
-1.4 \% \\
+2.9 \% \\
+3.5 \% \\
+0.3 \% \\
+3.0 \% \\
+1.4 \% \\
+0.6 \% \\
+0.3 \% \\
+0.6 \% \\
-2.2 \% \\
-1.8 \% \\
+3.8 \% \\
+1.4 \% \\
+2.4 \% \\
-1.3 \% \\
-0.3 \% \\
-0.6 \% \\
-0.6 \% \\
+12.0 \% \\
+0.3 \%\end{array}$ & $\begin{array}{r}2.3 \% \\
2.9 \% \\
4.2 \% \\
4.2 \% \\
2.0 \% \\
7.4 \% \\
7.5 \% \\
10.5 \% \\
4.7 \% \\
12.1 \% \\
3.5 \% \\
8.1 \% \\
4.0 \% \\
5.9 \% \\
3.5 \% \\
4.0 \% \\
18.3 \% \\
7.3 \% \\
6.8 \% \\
3.7 \% \\
6.4 \% \\
4 \cdot 2 \% \\
7.2 \% \\
4.4 \%\end{array}$ & $\begin{array}{l}.010 \\
.012 \\
.018 \\
.018 \\
.009 \\
.032 \\
.032 \\
.045 \\
.020 \\
.052 \\
.015 \\
.035 \\
.017 \\
.025 \\
.015 \\
.017 \\
.078 \\
.031 \\
.029 \\
.016 \\
.028 \\
.018 \\
.031 \\
.019\end{array}$ \\
\hline
\end{tabular}

(c)

\begin{tabular}{l|l|l|l|l|r|}
\hline 3 & 52 & $1 \cdot 123$ & - & & $19 \cdot 5 \%$ \\
5 & 52 & 1.132 & & & $15.0 \%$ \\
5 & 47 & 1.185 & & & $8.3 \%$ \\
3 & 38 & 1.308 & 1.250 & $+4.6 \%$ & $15.3 \%$ \\
5 & 38 & 1.315 & 1.250 & $+5.2 \%$ & $13.6 \%$ \\
5 & 38 & 1.332 & 1.250 & $+6.6 \%$ & $9.5 \%$ \\
3 & 42 & 1.212 & 1.250 & $-3.0 \%$ & $11.5 \%$ \\
5 & 38 & 1.278 & 1.250 & $+2.2 \%$ & $9.9 \%$ \\
\hline
\end{tabular}

For an accurate estimate, with known limits of error, a four-point assay may be used (Schild, 1942). With the information gained from the preliminary assay, two dilutions of the test solutions are prepared of approximately the same activity as the two standard solutions with which they are to be compared. It is convenient to have a ratio of 2: 1 between the higher and lower concentrations of both the test and standard solutions. These four solutions are filled into the four drug reservoirs. With the dose-order plugs arranged to give successive random sequences of the four doses, the apparatus is left running till 16 to 24 contractions have been obtained. The first four contractions are generally omitted when calculating the result.

The accuracy of such an assay is high for a biological method; routine measurements of solutions containing histamine released from tissues gave limits of error of 3 to $10 \%(P=0.05)$. The average value was about $6 \%$, corresponding to a standard deviation of about $2.5 \%$ (Table IIIa). Solutions of standard histamine assayed as "unknowns" gave similar limits. The actual deviations from the true results were known in this instance. They averaged $2.1 \%$ (Table IIIb). The details of 53 unselected assays are given in Table III, which includes the index of precision $(\mathrm{s} / \mathrm{b})$ of each experiment. The harmonic mean of $s / b$ (Gaddum, 1953) is 0.022. A typical assay is shown in Fig. 6 and its analysis of variance in Table IV.

When only small volumes of solution are available, insufficient for an ordinary assay, it is still possible to perform a fairly satisfactory assay by collecting the solutions after they have been in contact with the tissue and re-using them. The errors of an assay of this type are greater, because the solutions are gradually altered by diffusion in and out of the tissue, and by dilution with the washing solution still in contact with the tissue and organ bath. Nevertheless, the solutions can be

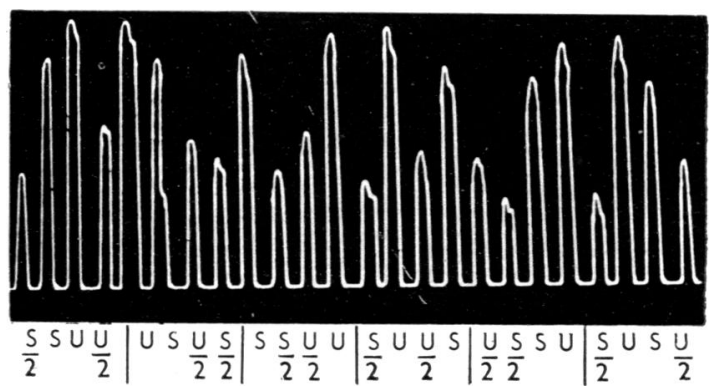

FIG. 6.-Typical four-point assay of histamine on guinea-pig ileum using the automatic apparatus. 
TABLE IV

ANALYSIS OF FOUR-POINT ASSAY SHOWN IN FIG. 6

\begin{tabular}{c|c|c|c|c|c|c|c}
\hline Dose & 1 & 2 & 3 & 4 & 5 & 6 & \\
\hline S/2 & 36 & 41 & 37 & 35 & 31 & 30 & 210 \\
U/2 & 52 & 49 & 51 & 45 & 44 & 42 & 283 \\
S & 80 & 77 & 78 & 74 & 73 & 70 & 452 \\
U & 90 & 91 & 86 & 87 & 83 & 85 & 522 \\
\hline Group totals $\ldots$ & 258 & 258 & 252 & 241 & 231 & 227 & 1,467 \\
\hline
\end{tabular}

Concentration of histamine solutions: $\begin{array}{ll}S / 2=4 \times 10^{-9} & S=8 \times 10^{-9} \\ U / 2=5 \times 10^{-9} & U=10 \times 10^{-9}\end{array}$

True relative potency $\overline{\mathrm{S}}=125 \%$

Estimated relative potency $=123 \%$

Limits of error from analysis of variance $(P=0.05) 119.5 \%$ to $126 \cdot 4 \%$.

ANALYSIS OF VARIANCE

\begin{tabular}{|c|c|c|c|c|}
\hline Source & & Sum of sqs. & d.f. & Mean sq. \\
\hline 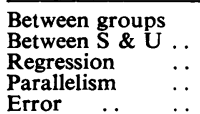 & $\begin{array}{l}\cdots \\
\cdots \\
\cdots \\
\cdots\end{array}$ & $\begin{array}{c}1,150 \\
852 \\
9,640 \\
0 \cdot 4 \\
49\end{array}$ & $\begin{array}{r}5 \\
1 \\
1 \\
1 \\
15\end{array}$ & $\begin{array}{r}230 \\
852 \\
9,640 \\
0 \cdot 4 \\
3 \cdot 3\end{array}$ \\
\hline
\end{tabular}

used three or four times and still provide a reliable assay. The average limit of error of 8 assays done in this way (Table IIIc) was $13 \%$.

\section{SUMMARY}

An automatic apparatus for pharmacological assays has been described which can be used for most types of assay on isolated preparations. All the operations of the assay cycle, such as adding and removing the drug solution, washing the tissue and controlling rotation of the drum, are performed automatically. The duration of each stage of the assay cycle can be varied independently, and the sequence in which several drug solutions are added to the tissue can be set to give any desired order.

Results obtained in 53 standard four-point assays of histamine on the guinea-pig ileum are given.

\section{REFERENCES}

Bovet, D., and Virno, M. (1952). Rendicont. ist. sup. san., $10,870$.

Bülbring, E. (1949). Brit. J. Pharmacol., 4, 234.

Gaddum, J. H. (1953). Pharmacol. Rev., 5, 103.

Gad and Lembeck, F. (1949). Brit. J. Pharmacol., 4, 401.

Godfrey, E. I., Mogey, G. A., and Taylor, D. L. (1950). Brit. J. Pharmacol., 5, 381.

Schild, H. O. (1942). J. Physiol., 101, 115. (1946). Brit.J. Pharmacol., 1, 135.

— (1947). Ibid., 2, 189. 